\title{
Tumor Targeting with Antibody-Functionalized, Radiolabeled Carbon Nanotubes
}

\author{
Michael R. McDevitt*1, Debjit Chattopadhyay*1, Barry J. Kappel ${ }^{1}$, Jaspreet Singh Jaggi ${ }^{1}$, Scott R. Schiffman ${ }^{1}$, \\ Christophe Antczak ${ }^{1}$, Jon T. Njardarson ${ }^{2}$, Renier Brentjens ${ }^{1}$, and David A. Scheinberg ${ }^{1}$ \\ ${ }^{I}$ Molecular Pharmacology and Chemistry Department, Departments of Medicine and Radiology, Memorial Sloan-Kettering Cancer \\ Center, New York, New York; and ${ }^{2}$ Department of Chemistry and Chemical Biology, Cornell University, Ithaca, New York
}

\begin{abstract}
Single-walled carbon nanotubes (CNT) are mechanically robust graphene cylinders with a high aspect ratio that are comprised of $\mathrm{sp}^{2}$-bonded carbon atoms and possessing highly regular structures with defined periodicity. CNT exhibit unique mechanochemical properties that can be exploited for the development of novel drug delivery platforms. We hypothesized that novel prototype nanostructures consisting of biologics, radionuclides, fluorochromes, and CNT could be synthesized and designed to target tumor cells. Methods: Tumor-targeting CNT constructs were synthesized from sidewall-functionalized, water-soluble CNT platforms by covalently attaching multiple copies of tumorspecific monoclonal antibodies, radiometal-ion chelates, and fluorescent probes. The constructs were characterized spectroscopically, chromatographically, and electrophoretically. The specific reactivity of these constructs was evaluated in vitro by flow cytometry and cell-based immunoreactivity assays and in vivo using biodistribution in a murine xenograft model of lymphoma. Results: A soluble, reactive CNT platform was used as the starting point to build multifunctional constructs with appended antibody, metal-ion chelate, and fluorescent chromophore moieties to effect specific targeting, to carry and deliver a radiometal-ion, and to report location, respectively. These nanoconstructs were found to be specifically reactive with the human cancer cells they were designed to target in vivo in a model of disseminated human lymphoma and in vitro by flow cytometry and cell-based immunoreactivity assays versus appropriate controls. Conclusion: The key achievement in these studies was the selective targeting of tumor in vitro and in vivo by the use of specific antibodies appended to a soluble, nanoscale CNT construct. The ability to specifically target tumor with prototype-radiolabeled or fluorescent-labeled, antibody-appended CNT constructs was encouraging and suggested further investigation of CNT as a novel delivery platform.
\end{abstract}

Key Words: single-walled carbon nanotubes; Rituximab; DOTA; nanoconstructs; nanotechnology

J Nucl Med 2007; 48:1180-1189

DOI: 10.2967/jnumed.106.039131

\footnotetext{
Received Dec. 21, 2006; revision accepted Mar. 7, 2007.

For correspondence or reprints contact either of the following:

David A. Scheinberg, MD, PhD, Molecular Pharmacology and

Chemistry Program, Sloan Kettering Institute, 1275 York Ave.,

Box 531, New York, NY 10021.

E-mail: d-scheinberg@mskcc.org

Michael R. McDevitt, PhD, Sloan Kettering Institute, 1275

York Ave., Box 531, New York, NY 10021.

E-mail: m-mcdevitt@ski.mskcc.org

${ }^{*}$ Contributed equally to this work.

COPYRIGHT @ 2007 by the Society of Nuclear Medicine, Inc.
}

$\mathbf{N}$ anostructures appended with biologic ligands can be designed to dimensionally approach the subcellular scale, thus providing a new generation of structures with potential applications in diagnostics and targeted therapy (1). Key functions for such nanoconstructs would be (i) specific targeting to a disease site, (ii) the ability to report information from the site, (iii) the ability to deliver a therapeutic "payload" at the site, and (iv) tolerability to the host. Such nanoconstructs that possess bifunctional (2) and multifunctional capabilities would be of interest for medical purposes. Single-walled carbon nanotubes (CNT) are unique materials that can be used as a platform for the synthesis of hybrid construct molecules capable of enabling multiple functions in vitro and in vivo. In this study, a CNT-antibody construct was designed and synthesized to specifically target the CD20 epitope on human Burkitt lymphoma cells, to report information regarding the binding of the construct to these cells, and to specifically deliver a radionuclide to these cells.

CNT are rolled graphene sheets that have been shown to be promising transporters of biologic cargo across cellular membranes (3-7). Moreover, CNT are mechanically robust (8), have a high aspect ratio, and all carbon atoms on the CNT are surface atoms that provide attachment sites for appending many ligands. The latter 2 features of CNT could lead to enormous amplification of one particular function or the ability to multifunctionalize the construct (9-11). For example, when ligands or radionuclide atoms are directly attached to antibodies, only a limited number can be attached before there is a loss in the inherent targeting function of the antibody $(12,13)$. Hence, CNT could be appropriate as delivery platforms for diagnostic or therapeutic agents where multiple copies of targeting, radionuclide, drug, or fluorescent agents could be attached. Kam et al. have demonstrated a selective uptake and destruction of cancer cells in vitro on activation of a folate functionalized CNT by near-infrared radiation (14). Issues regarding the toxicity of CNT materials have been raised $(15,16)$. However, recently it was reported that soluble, nonaggregated functionalized CNT are not toxic to primary immune cells (17) and that increased sidewall functionalization of CNT decreased the level of cytotoxicity toward human dermal fibroblasts (18). There were 2 studies 
of the in vivo biodistribution of functionalized CNT in mice in the literature $(19,20)$, but more data are needed with regard to the pharmacology, stability, and toxicity of CNTbased constructs. Previously, no antibody-CNT constructs have been specifically designed and engineered to target specific tissues or cell types, such as tumors in vivo. We hypothesized that the multiple simultaneous targeting, binding, delivery, and effector functions that would ensue might yield properties that are qualitatively different from those of the constituent parts (21). Herein, we report the synthesis of antibody-modified CNT constructs and demonstrate specific targeting both in vitro to a human tumor cell line and in vivo to a human tumor xenograft.

\section{MATERIALS AND METHODS}

\section{Synthesis and Characterization of Constructs}

$C N T$ 1. Raw single-walled carbon nanotubes $(\mathrm{CNT})$ were shortened and purified by oxidative acid digestion (22) to yield 1 (Fig. 1). Briefly, $60 \mathrm{mg}$ of CNT (lot 1280YJ; Nanostructured \& Amorphous Materials, Los Alamos, NM) were refluxed in $60 \mathrm{~mL}$ $2 \mathrm{M} \mathrm{HNO}_{3}$ (Fisher Scientific) for $48 \mathrm{~h}$. Sonication for $0.5 \mathrm{~h}$ was performed at $70^{\circ} \mathrm{C}$ with $100 \mathrm{~W}$ with a Biologics model $300 \mathrm{~V} / \mathrm{T}$ Ultrasonic Homogenizer using the 3/8-in-diameter stepped titanium tip. The CNT were then refluxed for an additional $10 \mathrm{~h}$ in $2 \mathrm{M} \mathrm{HNO}_{3}$.

$\mathrm{CNT}-\left(\mathrm{NH}_{2}\right) \mathbf{2}$. The sidewall functionalization of $\mathbf{1}$ with amino groups was performed using the azomethine ylide cycloaddition route (23) and afforded water-soluble, reactive CNT-( $\left.\mathrm{NH}_{2}\right)$ (Fig. 1, compound 2). The soluble 2 was examined by atomic force microscopy (AFM) using a model MFP-3D microscope (Asylum Research), and the moles of amine per gram CNT were quantified spectrophotometrically (24).

CNT- $\left(\mathrm{NH}_{2}\right)($ DOTA $) 3$. A fraction of the amine functionalities on 2 were then modified with the bifunctional chelate 2-(4-isothiocyanatobenzyl)-1,4,7,10-tetraazacyclododecane-1,4,7,10-tetraacetic (DOTA-NCS; Macrocyclics, Inc.). The DOTA-NCS was attached to the CNT via a thiourea linkage, which is quite stable under physiologic conditions in vivo and in vitro (25). Buffers, reagents, and chromatographic media were rendered metal free (26) to prepare CNT-( $\left.\mathrm{NH}_{2}\right)$ (DOTA). Briefly, $20 \mathrm{mg}$ of $\mathbf{2}(1.76 \mathrm{mmol}$ amine per gram CNT) in metal-free water (MFW) were mixed with 0.05 mmol of DOTA-NCS at $\mathrm{pH} 9.5$ in a $1 \mathrm{mM}$ bicarbonate buffer for $30 \mathrm{~min}$ at room temperature (0.7 amine: 1 DOTA-NCS). The product was purified using a 10DG column (BioRad) with MFW as the mobile phase. The CNT-( $\left.\mathrm{NH}_{2}\right)(\mathrm{DOTA})$ product (Fig. 1, compound $\mathbf{3}$ ) was lyophilized to give a solid powder. The extent of DOTA capable of binding metals per construct $\mathbf{3}$ was assayed spectrophotometrically (27), and the residual amines were again assayed (24).

CNT-(DOTA)(Mal) 4. The remaining free-amine groups on $\mathbf{3}$ were derivatized using $0.5 \mathrm{mmol}$ of the heterobifunctional crosslinker succiminidyl-4-( $N$-maleimidomethyl)cyclohexane-1-carboxy(6-amidocaproate) (LC-SMCC; Pierce Biotechnology, Inc.) per gram of $\mathbf{3}(0.27 \mathrm{mmol}$ amine per gram CNT) in anhydrous $N$, $N$-dimethylformamide (DMF) (1 amine:90 LC-SMCC). The $\mathrm{pH}$ was adjusted to 7.0 by adding sodium bicarbonate to the reaction mixture, and the reaction was carried out over $2 \mathrm{~h}$ at room temperature. The CNT-(DOTA)(Mal) product (Fig. 1, compound 4) was purified using a 10DG column with a $5 \mathrm{mM}$ ethylenedia- minetetraacetic acid/phosphate-buffered saline (EDTA/PBS) buffer, $\mathrm{pH}$ 6.4, mobile phase. The amount of maleimide that was appended per gram CNT was assayed by reacting an aliquot of $\mathbf{4}$ with a known excess amount of cysteine containing trace amounts of ${ }^{35} \mathrm{~S}$-labeled cysteine (Perkin Elmer).

CNT-(DOTA)(Rituximab) $5 \boldsymbol{a}$. Reactive sulfhydryl groups were introduced onto Rituximab (Genentech, Inc.) and Lintuzumab (Protein Design Laboratories) antibodies by reaction with 2iminothiolane- $\mathrm{HCl}$ (Traut's reagent). A 10-fold molar excess of Traut's reagent (Pierce Biotechnology, Inc.) was added to $2 \mathrm{mg}$ of antibody in $0.25 \mathrm{~mL}$ PBS/5 mM EDTA buffer, and the $\mathrm{pH}$ was increased to 8-9 with $1 \mathrm{M}$ bicarbonate buffer. The reaction was allowed to proceed for $1 \mathrm{~h}$ at ambient temperature. The thiolatedantibody was purified from excess Traut's reagent using a 10DG column. The number of reactive thiol groups that were appended onto the antibody was determined by Ellman's assay (28).

The thiolated-antibody was then conjugated to 4 . Briefly, a ratio of $0.05 \mathrm{mmol}$ of thiolated-antibody per gram of $\mathbf{4}(0.09 \mathrm{mmol}$ maleimide per gram CNT) was used for this reaction at ambient temperature, $\mathrm{pH} 7.5$, for $2 \mathrm{~h}$. After $2 \mathrm{~h}$, any unreacted thiol groups on the antibody were quenched by the addition of excess maleimidobutyric acid (Aldrich) to prevent cross-linking of the proteins with CNT. Note, the same procedures were used for conjugation of Rituximab and Lintuzumab to 4 ; further, in the text and figures, the antibody-appended constructs 5 and $\mathbf{7}$ were categorized with the letters $\mathbf{a}$ and $\mathbf{b}$ to denote the Rituximab and Lintuzumab modifications, respectively.

The CNT-(DOTA)(Rituximab) product (Fig. 1, compound 5a) or $\mathbf{5 b}$ was purified and characterized by high-performance liquid chromatography (HPLC) using a Beckman Coulter System Gold Bioessential 125/168 diode-array detection instrument (Beckman Coulter). A Superdex 200 stationary phase (Amersham Biosciences) and a $100 \mathrm{mM} \mathrm{NaCl} / 40 \mathrm{mM}$ Tris- $\mathrm{HCl}$ mobile phase at a flow rate of $0.5 \mathrm{~mL} / \mathrm{min}$ were used to effect separation of the construct from any unreacted antibody and CNT. Construct $\mathbf{5}$ was also analyzed using gel electrophoresis with a $7.5 \%$ acrylamide gel that was run under nonreducing and reducing conditions. The gels were developed with silver stain. Note that underivatized CNT does not stain. The antibody-to-CNT ratio was determined by a combination of (i) UV-Vis (ultraviolet-visible) spectroscopy (at $600 \mathrm{~nm}$ ) to measure the CNT concentration from the linear region of a standard curve of absorbance at $600 \mathrm{~nm}$ versus different concentrations of CNT and (ii) the Lowry assay (determine the total protein concentration at $750 \mathrm{~nm}$ ) to measure the antibody concentration.

The construct 4 was preconjugated to the fluorescent probe 5-((2-(and-3)-S-(acetylmercapto)succinoyl)amino)fluorescein ([SAMSA-fluorescein]; Molecular Probes) and then modified with thiolated-antibody for flow cytometry experiments. SAMSA-fluorescein was activated and then reacted with the thiol-reactive $\mathbf{4}$, purified using a 10DG column and PBS mobile phase to obtain the fluorescent conjugate CNT-(DOTA)(Mal)(SAMSA). This SAMSA modification of the CNT was performed under substoichiometric conditions, relative to the number of maleimides, to leave maleimides available for attachment of antibodies. Thiolated-antibody was then reacted and purified as described to yield SAMSA-5.

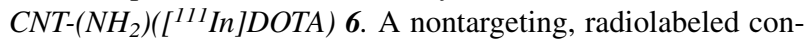
struct 6 was prepared by adding $111-185 \mathrm{MBq}$ of acidic ${ }^{111} \mathrm{In}$ chloride (Perkin Elmer) to $0.150 \mathrm{mg}$ of $\mathbf{3}(10 \mathrm{~g} / \mathrm{L})$ in MFW and $0.050 \mathrm{~mL}$ of $3 \mathrm{M}$ ammonium acetate (Aldrich) to yield a pH 5.5 solution. The reaction mixture was heated to $60^{\circ} \mathrm{C}$ for $30 \mathrm{~min}$ and then purified using a $10 \mathrm{DG}$ column with $1 \%$ human serum albumin 


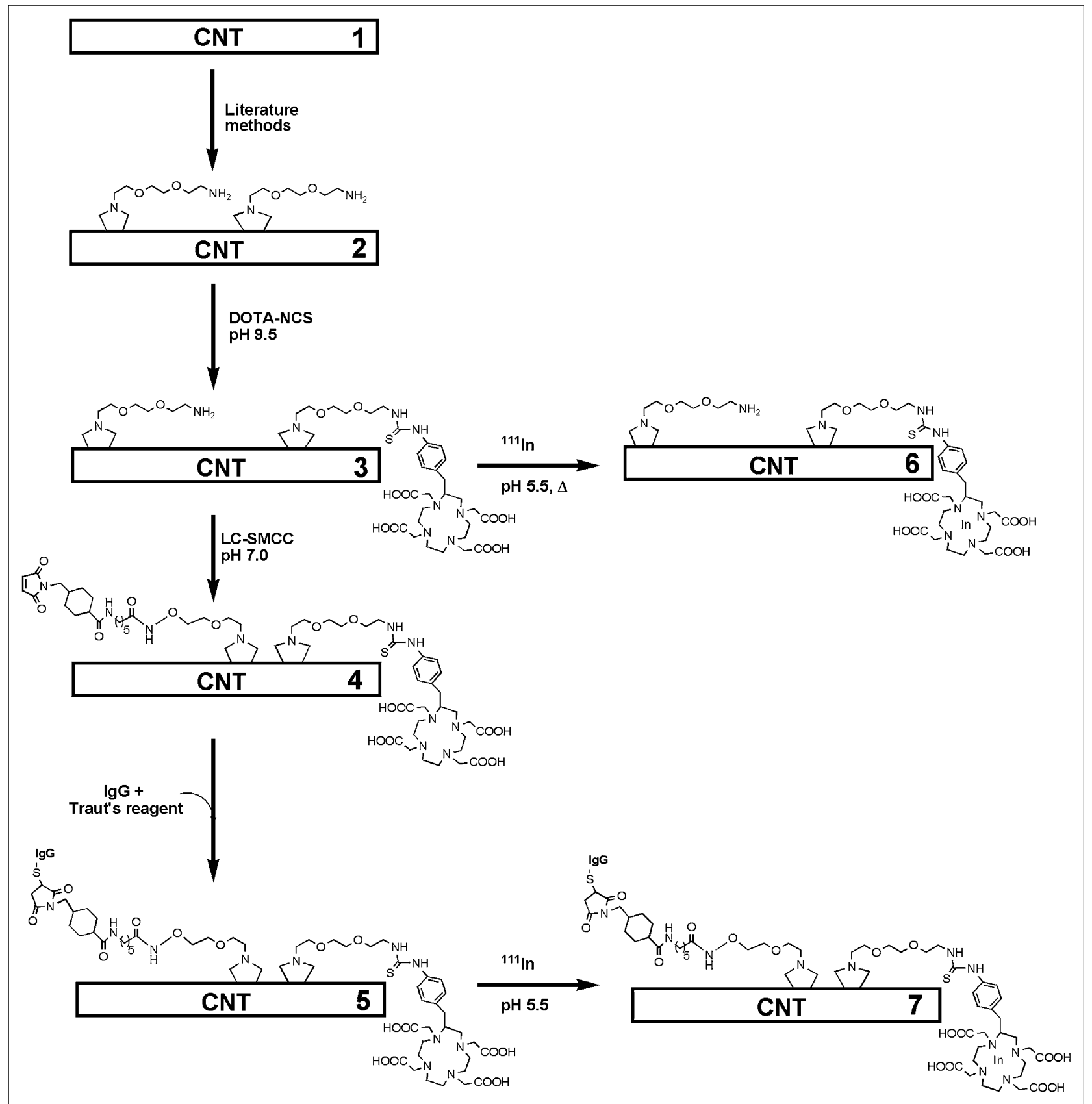

FIGURE 1. Reaction scheme for all synthetic CNT constructs. Only the key appended chemical and biologic constituents are shown for clarity. IgG is abbreviation for the antibody. Note, in the text, antibody-appended constructs $\mathbf{5}$ and $\mathbf{7}$ will be further categorized with letters $\mathbf{a}$ and $\mathbf{b}$ to denote the Rituximab and Lintuzumab modifications, respectively.

(HSA; Swiss Red Cross) in $0.9 \% \mathrm{NaCl}$ (Abbott Laboratories) as the mobile phase. Radioactivity was assayed in a Squibb CRC-17 Radioisotope Calibrator or equivalent (E.R. Squibb and Sons, Inc.).

A small aliquot of $\mathbf{6}$ was used to determine the radiochemical purity by instant thin-layer chromatography silica gel (ITLC-SG) using silica gel-impregnated paper (Gelman Science Inc.) developed using 2 different mobile phases. Mobile phase I was $10 \mathrm{mM}$ EDTA and mobile phase II was $9 \% \mathrm{NaCl} / 10 \mathrm{mM} \mathrm{NaOH}$. The strips were counted using an Ambis 4000 gas-ionization detection system (Ambis Inc.).

Further characterization of $\mathbf{6}$ was performed by C18 reversephase HPLC, using a Beckman Coulter System Gold Bioessential
125/168 diode-array detection instrument equipped with an in-line $\gamma$-RAM model 3 radioactivity detector (IN/US).

CNT-([111 In]DOTA)(Rituximab) $7 \boldsymbol{a}$ and CNT-([111 In]DOTA) (Lintuzumab) 7b. The specific CNT-([111In]DOTA)(Rituximab) construct (Fig. 1, compound 7a) or control CNT-([111 In]DOTA) (Lintuzumab) construct (7b) was prepared by adding 111-185 $\mathrm{MBq}$ of acidic ${ }^{111} \mathrm{In}$ chloride to $0.50 \mathrm{mg}$ of $\mathbf{5 a}$ or $\mathbf{5 b}(50 \mathrm{~g} / \mathrm{L})$ in MFW and $0.050 \mathrm{~mL}$ of $3 \mathrm{M}$ ammonium acetate to yield a $\mathrm{pH} 5.5$ solution. The reaction mixture was maintained at ambient temperature for $30 \mathrm{~min}$ and then purified using a 10DG column with $1 \%$ HSA $/ 0.9 \% \mathrm{NaCl}$. The radiochemical purity was determined by the ITLC-SG methods described. 


\section{Radiolabeled Antibody Controls}

The antibodies Rituximab and Lintuzumab were radiolabeled for performing control experiments using the published 2-step method (29) with ${ }^{111}$ In instead of ${ }^{225}$ Ac. The radiochemical purity was determined by the ITLC-SG methods described.

\section{Stability of CNT-([111 In]DOTA)(Rituximab) in Human Plasma In Vitro}

The stability of $7 \mathbf{a}$ was determined in vitro by incubating the radiolabeled construct in human plasma at physiologic temperature for $96 \mathrm{~h}$. An aliquot of 7a in plasma was removed at 24-h intervals and the radiochemical purity was determined by ITLC as described previously.

\section{Flow Cytometric Analysis of CNT- (DOTA)(Rituximab)(SAMSA) Cell Binding In Vitro}

Flow cytometric analysis of the Daudi $(\mathrm{CD} 20+, \mathrm{CD} 33-)$ and HL60 (CD33+, CD20-) cell lines was performed with the SAMSA-5a and control SAMSA-5b constructs. Cells were acquired on an FC500 cytometer (Beckman Coulter) and analyzed with FlowJo software (Tree Star, Inc.).

\section{Cell-Based Immunoreactivity of CNT- ([111/n]DOTA)(Rituximab) In Vitro}

The cell binding efficiency (25) of 7a was determined using specific Daudi target cells and control HL60 cells. Briefly, 7 nanograms of $7 \mathbf{a}$ in $2 \% \mathrm{HSA} /$ bovine serum albumin (BSA; Sigma) were incubated with $5 \times 10^{6} \mathrm{CD} 20^{+}$specific Daudi cells $(n=3)$ or $3 \times 10^{6}$ nonspecific CD20- HL60 cells $(n=3)$ in a total volume of $<0.20 \mathrm{~mL}$ at $4^{\circ} \mathrm{C}$ and $37^{\circ} \mathrm{C}$. The percent cell-associated activity was measured after 30,60 , and $120 \mathrm{~min}$ incubation of $\mathbf{7 a}$ with the cells. The cells were washed twice with $1 \mathrm{~mL}$ of cold PBS and pelleted $\left(1,200 \mathrm{rpm}\right.$ for $5 \mathrm{~min}$ at $\left.4^{\circ} \mathrm{C}\right)$.

\section{Generation of GFP-FFLuc ${ }^{+}$Transfected Daudi Tumor Cell Line}

The green fluorescent protein (GFP) and firefly luciferase (FFLuc) gene (Clonetech Laboratories) was subcloned into the SFG retroviral vector, and vesicular stomatitus virus G glycoprotein (VSV-G) retroviral supernatants derived from gpg29 fibroblasts transduced with the resulting SFG(GFP-FFLuc) plasmid were used to transduce Daudi tumor cells as described elsewhere $(30,31)$. The resulting cells were sorted by flow cytometry for GFP expression to isolate a homogeneous population of $\mathrm{GFP}^{+} / \mathrm{FFLuc}^{+}$ Daudi tumor cells for expansion. This modification permitted us to monitor disease progression by bioluminescence imaging (BLI) (32) and to quantitate the extent of lymphoma in the bone marrow.

\section{Biodistribution of CNT-([111/n]DOTA)(Rituximab) and Controls in Mice}

The biodistribution and tumor targeting specificity of $\mathbf{7 a}$ was evaluated against different controls in a murine model of disseminated lymphoma (34) using the $\mathrm{GFP}^{+} / \mathrm{FFLuc}^{+}$Daudi cell line. The tumor was introduced by injecting 5 million cells into each of the female C.B.-17 severe combined immunodeficiency (scid) mice (8- to 10-wk old; Taconic Farms) intravenously via the retroorbital sinus route. Tumor growth in mice was determined by BLI using a Xenogen IVIS Optical Imaging System (Xenogen Corp.). Imaging was performed on mice that received an intraperitoneal injection of $3 \mathrm{mg}$ of D-Luciferin (Xenogen) per mouse.

On day 28 after tumor infusion, the tumor-bearing mice were separated into 4 groups; an additional 2 groups of scid mice with no tumor were included as control. Biodistribution studies were performed at $24 \mathrm{~h}$ after injection of the radiolabeled constructs. Group 1 mice $(n=6)$, with tumor, received $0.018 \mathrm{mg}$ of the specific construct 7a. Group 2 mice $(n=6)$, with tumor, received $0.018 \mathrm{mg}$ of the nonspecific control construct $\mathbf{7 b}$. Group 3 mice $(n=3)$, with no tumor, received $0.018 \mathrm{mg}$ of the specific construct 7a. Group 4 mice $(n=3)$, with no tumor, received $0.018 \mathrm{mg}$ of the nonspecific control construct $7 \mathbf{b}$. Group 5 mice $(n=4)$, with tumor, received $0.010 \mathrm{mg}$ of the nontargeting construct $\mathbf{6}$ as a control for CNT. Group 6 mice $(n=6)$, with tumor, received $0.015 \mathrm{mg}$ of the $\left[{ }^{111} \mathrm{In}\right]$ Rituximab targeting antibody as a positive control. All constructs were adjusted to a specific activity of 37 $\mathrm{GBq} / \mathrm{g}$ and were administered intravenously by the retroorbital sinus route. Mice in groups 1, 2, 5, and 6 were xenografted $28 \mathrm{~d}$ before this biodistribution study with the $\mathrm{GFP}^{+} / \mathrm{FFLuc}^{+}$Daudi tumor.

For all in vivo experiments, housing and care were in accordance with the Animal Welfare Act and the Guide for the Care and Use of Laboratory Animals. The animal protocols were approved by the Institutional Animal Care and Use Committee at Memorial Sloan-Kettering Cancer Center.

\section{Flow Cytometric Analysis of GFP-Expressing Daudi Cell Content of Bone Marrow}

Twenty-eight days after intravenous injection of $\mathrm{GFP}^{+} / \mathrm{FFLuc}^{+}$ Daudi cells into mice, femurs from tumor- and nontumor-bearing (control) mice were removed to assess the amount of human lymphoma present in the bone marrow. Femurs were crushed by mortar and pestle, sieved to recover the bone marrow that was suspended in PBS/0.5\% BSA/0.02\% sodium azide (FACS) buffer. Cells were acquired on an FC500 cytometer and analyzed with FlowJo software for GFP expression.

\section{Biodistribution of CNT-( $\left.\mathrm{NH}_{2}\right)\left(\left[{ }^{111} \mathrm{In}\right] \mathrm{DOTA}\right)$ and Controls in Mice}

The biodistribution of the nontargeting, radiolabeled construct prototype, $\mathbf{6}$, was investigated in normal, nontumor-bearing mice. Female BALB/c mice, 8- to 12-wk old (Taconic Farms), were placed into 5 groups of 3 animals per group. Briefly, $0.007 \mathrm{mg}$ of 6 (specific activity, $37 \mathrm{GBq} / \mathrm{g}$ ) in $0.1 \mathrm{~mL}$ of $1 \%$ HSA was injected intravenously per mouse via the retroorbital sinus. One group of mice was sacrificed at each of the following time points-1, 24, 96, 216, and $360 \mathrm{~h}$-and tissue samples, including blood, brain, lung, heart, adipose tissue, liver, kidney, spleen, and femur were harvested, weighed, and counted using a Cobra $\gamma$-counter (Packard Instrument Co., Inc.) with a 315- to $435-\mathrm{keV}$ window. Standards of the injected formulation were counted to determine the percentage injected dose per gram $(\% \mathrm{ID} / \mathrm{g})$. The control for this study was a mixture of ${ }^{111} \mathrm{In}-\mathrm{DOTA}$ and 2 . This mixture was prepared by adding $37 \mathrm{MBq}$ of acidic ${ }^{111} \mathrm{In}$ chloride to $0.5 \mathrm{mg}$ (10 $\mathrm{g} / \mathrm{L}$ in MFW) of 1,4,7,10-tetraazacyclododecane-1,4,7,10tetraacetic acid (DOTA; Macrocyclics, Inc.) and $0.050 \mathrm{~mL}$ of 3 $\mathrm{M}$ ammonium acetate to yield a $\mathrm{pH} 5.5$ solution. The reaction mixture was heated to $60^{\circ} \mathrm{C}$ for $30 \mathrm{~min}$ and then purified as described; $0.150 \mathrm{mg}$ of 2 in MFW was added to the ${ }^{111} \mathrm{In}$-DOTA product and mixed.

\section{Statistical Analysis of Data}

Graphs were constructed and statistical data were evaluated using Graphpad Prism 3.0 (Graphpad Software, Inc.). Statistical comparison between 2 experimental groups was performed using a $t$ test (unpaired comparison); comparison of 3 groups was 
performed with the 1-way ANOVA using Bonferroni's multiple comparison post hoc analysis. All statistical comparisons were 2 -sided, and the level of statistical significance was set at $P<0.05$.

\section{RESULTS}

\section{Synthesis, Radiolabeling, and Characterization of CNT Constructs}

Construct 2 was examined by AFM, and a distribution of lengths, ranging from 200 to $1,000 \mathrm{~nm}$, as well as some aggregated bundles with diameters not greater than $10 \mathrm{~nm}$ were observed. Individual CNT had a diameter of $1.4 \mathrm{~nm}$. The amine content of $\mathbf{2}$ was determined to be $1.76 \mathrm{mmol}$ amines per gram CNT.

Construct 3 was assayed to have $0.30 \mathrm{mmol}$ of DOTA capable of binding metal per gram CNT. Because each thiourea-linked DOTA subtracted 1 amine from the total number, 3 was again assayed to quantify the amount of unreacted amines that remained, and $0.27 \mathrm{mmol}$ amine per gram CNT was found. The cysteine assay indicated that 0.09 mmol maleimide per gram CNT had been incorporated onto 4. It was determined that there were 5-7 thiols introduced per antibody.

Construct 5 was purified and analyzed using HPLC (supplemental Table S1 and supplemental Figures S1 and $\mathrm{S} 2$ are available online only at http://jnm.snmjournals.org; see Fig. S1). Construct 5 typically eluted at 18 min, whereas the free antibody (28 $\mathrm{min})$ and unreacted CNT (42 min) eluted later. Diode-array detection of the chromatographed product fraction (18-min peak) yielded a composite spectral fingerprint of the CNT portion of the construct (broad absorbance between 250 and $500 \mathrm{~nm}$ ) and the antibody portion (absorbance at $280 \mathrm{~nm}$ ). In a control experiment, the chromatographic retention times and spectral fingerprints of the individual components (Rituximab antibody and 2) used to prepare 5a were measured and confirmed these assignments.

Construct 5 was also analyzed using gel electrophoresis run under both nonreducing and reducing conditions and yielded a pattern of several high-molecular-weight bands with protein components far larger than the molecular weight of only the reduced antibody.

The antibody-to-CNT ratio was determined by a combination of UV-Vis spectroscopy to measure the CNT concentration and Lowry assay to measure the antibody concentration. The constructs $\mathbf{5 a}$ and $\mathbf{5 b}$ contained 0.02 mmol antibody per gram CNT (this corresponds to 6 antibodies appended per 200-nm-long CNT). These results confirmed the presence of a construct with multiple antibody molecules covalently linked to a CNT.

Construct 6 had radiochemical purity of $95 \%$ as determined by ITLC-SG. The $\mathrm{R}_{\mathrm{f}}$ of the radiolabeled CNT construct was 0 , and both any unchelated ${ }^{111}$ In species and unattached metal chelates were characterized by an $R_{f}$ of 1 in mobile phase I. In mobile phase II, $\mathbf{6}$ and unchelated ${ }^{111}$ In were characterized by an $\mathrm{R}_{\mathrm{f}}$ of 0 ; the $\mathrm{R}_{\mathrm{f}}$ of any unattached chelated metal species was 1 . The specific activities of the constructs ranged from 18.5 to 1,110 $\mathrm{GBq} / \mathrm{g}$. HPLC analysis of 6 identified a sharp peak that was attributed to the construct based on the characteristic CNT spectral signature and a corresponding radioactivity trace. The radiochemical purity of $7 \mathbf{a}$ and $7 \mathbf{b}$ was $95 \%$ and the radiolabeled Rituximab was $98 \%$ as determined by the ITLC-SG methods described.

\section{In Vitro Analyses of Construct Stability, Cell Binding, and Immunoreactive Fraction}

The stability of $\mathbf{7 a}$ in human plasma at physiologic temperature was examined for a period of $96 \mathrm{~h}$ in vitro, and there was no significant change in the radiochemical purity during the course of this experiment; the purity was assayed to range between $90 \%$ and $94 \%$, suggesting that the $\left[{ }^{111} \mathrm{In}\right]$ DOTA-to-CNT thiourea bond and the ${ }^{111}$ In-to-DOTA coordination bonds were stable in human plasma over this 4-d period.

The cell-binding specificity of the construct SAMSA-5a was directly measured in vitro by flow cytometry. The construct SAMSA-5a showed specific binding to CD20 ${ }^{+}$Daudi cells but not to CD20- HL60 cells (Fig. 2A). Similarly the control construct SAMSA-5b was observed to bind specifically to $\mathrm{CD} 33^{+}$HL60 cell lines but not to CD33- Daudi cells (data not included).

The immunoreactive fraction of $\mathbf{7 a}$ was measured in vitro using a live cell assay (25). On the basis of the time and temperature data from this assay, the binding kinetics of the construct appeared to be diffusion controlled, and the binding efficiency increased with both time and temperature (Fig. 2B). The construct 7a approached maximum binding after about $1 \mathrm{~h}$, whereas the binding to the control cells was less. The maximum binding for this construct was $29 \% \pm$ $0.5 \%$, similar to the immunoreactive fraction of radiolabeledRituximab measured previously as $42 \% \pm 17 \%$ (34) (and repeated here; data not shown). The binding of 7 a to $\mathrm{CD} 20^{+}$ Daudi cells at $37^{\circ} \mathrm{C}$ and $4^{\circ} \mathrm{C}$ was statistically different $(P<$ $0.0001)$ as was the binding of $7 \mathbf{a}$ to Daudi cells and CD20HL60 cells at $37^{\circ} \mathrm{C}(P<0.0001)$.

\section{GFP $^{+}$/FFLuc ${ }^{+}$Daudi Tumor Model in scid Mice}

Twenty-eight days after intravenous injection of $\mathrm{GFP}^{+}$/ FFLuc $^{+}$Daudi cells into scid mice, macroscopic, disseminated tumors developed in the bone marrow and spleen as well as in kidneys, liver, lungs, ovaries, and adipose tissue. BLI clearly showed the presence of lymphoma in the femur and spine, spleen, kidney, and, to a lesser extent, liver. The amount of tumor per tissue on a per-weight basis was spine (bone marrow) $>$ spleen $>$ kidney $>$ liver (Fig. S2).

The amount of tumor in the bone marrow was quantified $28 \mathrm{~d}$ after tumor xenograft. Bone marrow cells from both tumor- and nontumor-bearing mice were harvested and prepared as a single cell suspension. Flow cytometry on the bone marrow - derived cells $\left(37 \times 10^{6}\right.$ cells $)$ indicated that about $37 \%$ were GFP+ Daudi cells. Figure 3 demonstrates 


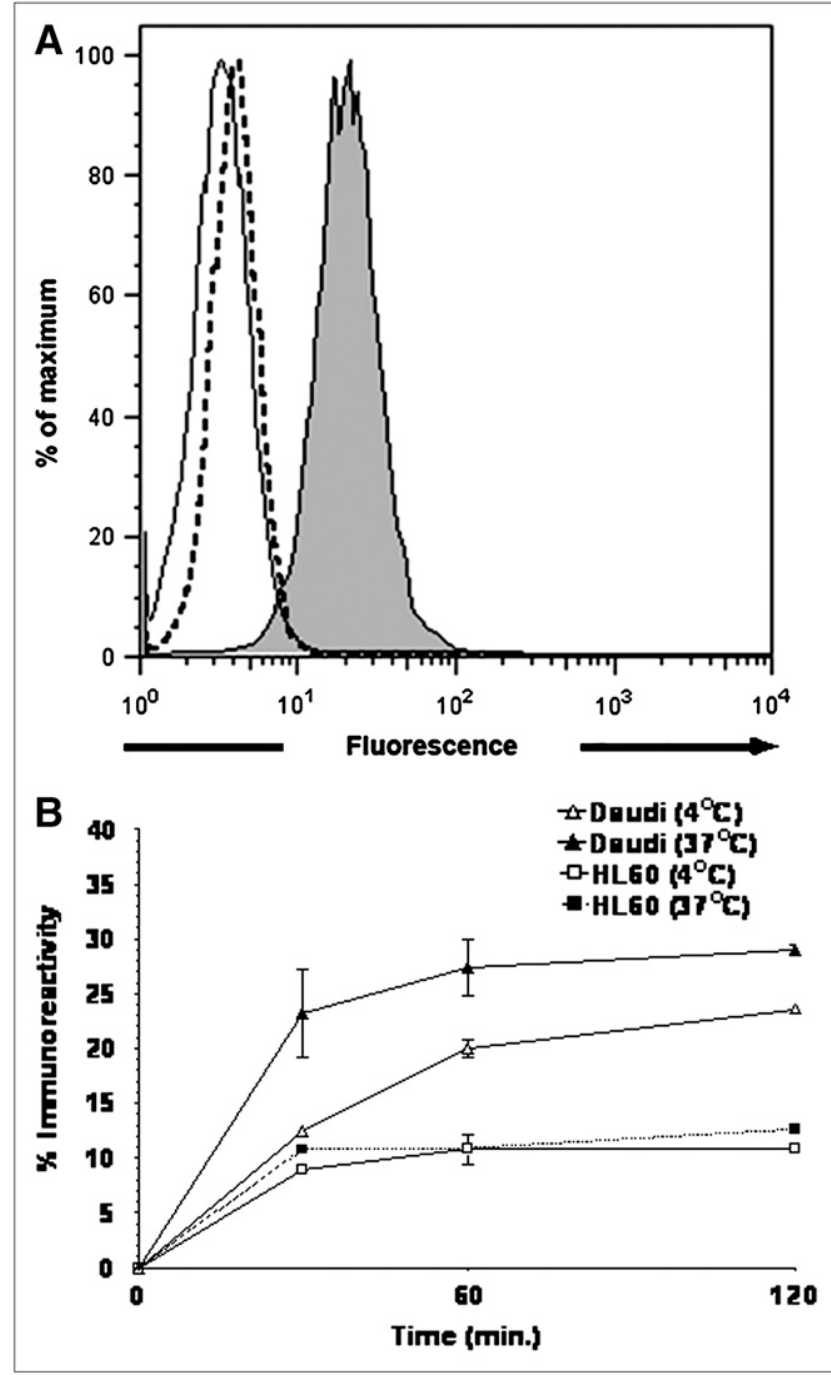

FIGURE 2. (A) Flow cytometric histograms demonstrating specific binding of fluorescent-labeled construct SAMSA-5a to Daudi cells. Shown is overlay of single-parameter histograms of (i) Daudi cells + SAMSA-5a (shaded histogram), (ii) Daudi cells + SAMSA-5b (solid-line trace), and (iii) HL60 cells + SAMSA-5a (dashed-line trace). Fluorescence being directly measured is due to the SAMSA chromophore that is attached to the CNT backbone. (B) Cell-based immunoreactivity of 7 a as a function of time and temperature vs. specific (Daudi) and nonspecific (HL60) cell lines. Mean \pm SD values for each measurement are plotted.

that the fluorescent $\mathrm{GFP}^{+} / \mathrm{FFLuc}^{+}$Daudi cells were present in the marrow in the femurs of tumor-bearing mice.

\section{Biodistribution of CNT-([111In]DOTA)(Rituximab) Construct and Control Constructs}

In the femurs of tumor-bearing mice, the mean $\% \mathrm{ID} / \mathrm{g}$ values were greater for the specific 7a construct (group 1) than for the nonspecific $\mathbf{7 b}$ construct (group 2) $(P<$ 0.0001) (Fig. 4A; Table S1). Figure 5 displays the data for all groups for the tissues measured. The mean $\% \mathrm{ID} / \mathrm{g}$ values were 5.6-fold greater (Fig. 4A) for the group 1 mice

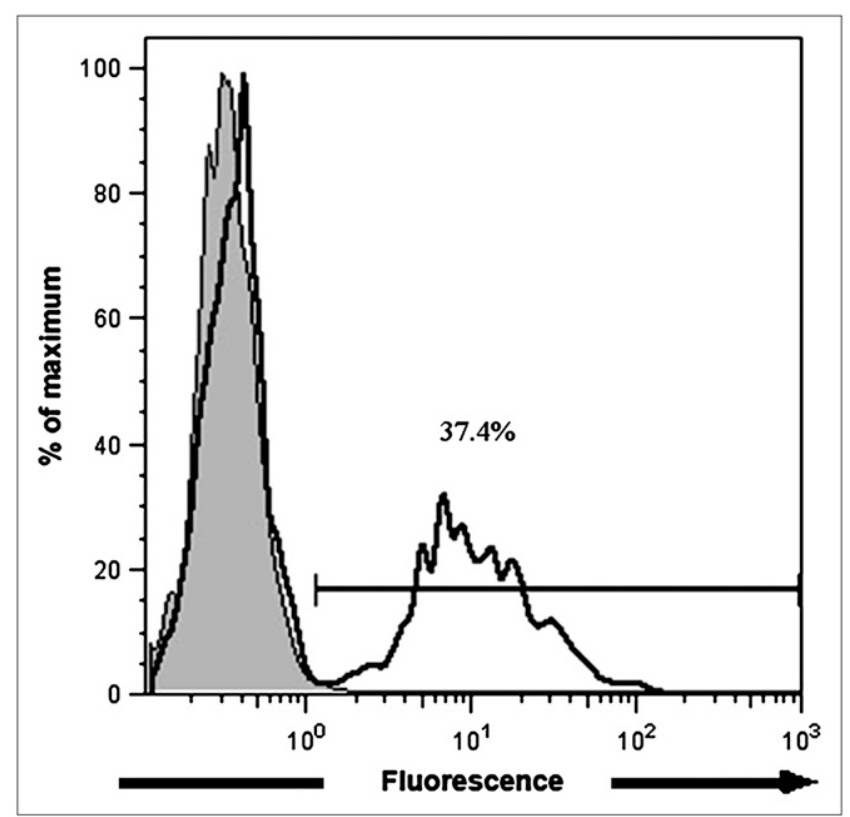

FIGURE 3. Flow cytometric demonstration of human lymphoma cells present in femurs of tumor-bearing mice $28 \mathrm{~d}$ after intravenous injection of $\mathrm{GFP}^{+} / \mathrm{FFLuc}^{+}$Daudi cells into mice. Shown is overlay of single-parameter histograms of tumorbearing (solid-line trace) and nontumor-bearing (shaded histogram) mice. Fluorescence being measured is due to the GFP signal.

with tumors compared with the group 3 control mice $(P<$ 0.0001). More of the specific construct 7a (group 1) accumulated in the femur of mice with tumors than did nontargeting, nonantibody-appended construct 6 (group 5) $(P<0.0001)$ (Fig. 4A).

The specific targeting antibody construct $\left[{ }^{111}\right.$ In]Rituximab (group 6) served as a positive control for the antibody portion of the construct 7a. The femurs of mice in group 1 accumulated $6.23 \pm 0.42 \% \mathrm{ID} / \mathrm{g}$, whereas the femurs in group 6 mice accumulated $11.4 \pm 3.32 \% \mathrm{ID} / \mathrm{g}$; these values were significantly different $(P=0.0035)$.

The specific construct 7a (group 1) also showed statistically greater uptake $(P=0.0035)$ in spleen than the nonspecific construct $\mathbf{7 b}$ (group 2) of tumor-bearing mice (Fig. 4B).

The covalent attachment of antibodies to the CNT scaffold dramatically altered the kidney biodistribution and pharmacokinetics as illustrated by the comparison of 6 and $7 \mathbf{a}$ in tumor-bearing (groups 1 and 5 had $10.5 \pm 2.47$ $\% \mathrm{ID} / \mathrm{g}$ and $28.8 \pm 0.97 \% \mathrm{ID} / \mathrm{g}$, respectively) versus nontumor-bearing mice (group 3 had $1.63 \pm 0.06 \% \mathrm{ID} / \mathrm{g}$ and 6 in another biodistribution study [Figs. 5 and 6 ] had $41.06 \pm$ $3.09 \% \mathrm{ID} / \mathrm{g}$ ) at $24 \mathrm{~h}$.

\section{Biodistribution of CNT-( $\left.\mathrm{NH}_{2}\right)\left(\left[{ }^{111}\right.\right.$ In]DOTA) Construct and Controls in Mice}

Clearance of the nontargeting, radiolabeled construct 6 from the blood compartment was rapid. After $1 \mathrm{~h}, 2.76 \pm$ $0.14 \% \mathrm{ID} / \mathrm{g}$ was still in the blood and, after $20 \mathrm{~h}$, only 


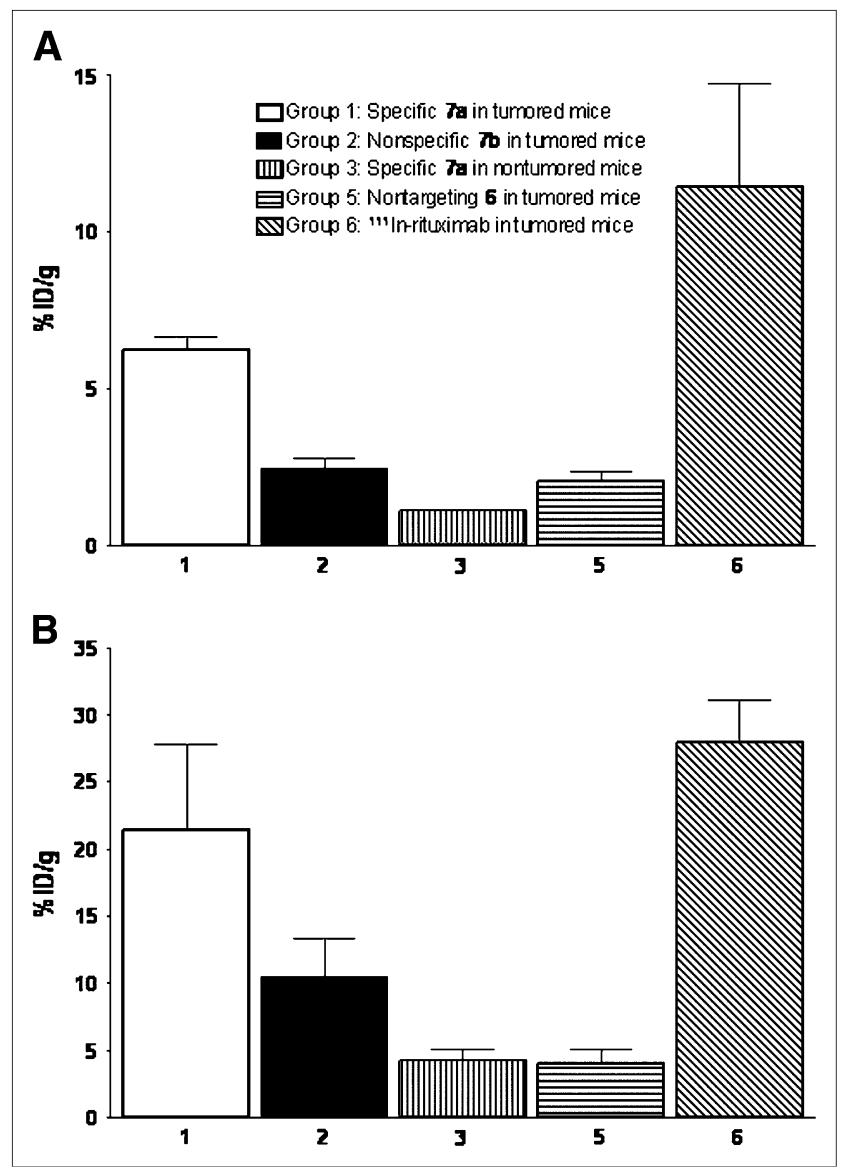

FIGURE 4. Lymphoma-infiltrated femur (A) and spleen (B) uptake data (\%ID/g values [mean \pm SD]) of CNT constructs and controls in scid mice with and without $\mathrm{GFP}^{+} / \mathrm{FFLuc}^{+}$Daudi tumor.

$0.41 \pm 0.05 \% \mathrm{ID} / \mathrm{g}$ was in circulation. The experiment was continued for $15 \mathrm{~d}$, at which time no activity was found in circulation. Tissue harvest indicated that the major sites of ${ }^{111}$ In accumulation were the kidney, liver, spleen, and, to a much lesser extent, bone (Fig. 6). ${ }^{111}$ In cleared the kidneys more rapidly than the spleen and liver. Urine samples were collected from mice $1 \mathrm{~h}$ after injection. Radioactivity was noted and the samples were analyzed using the ITLC methods described. The activity remained at the origin of strips submitted to mobile phase I, indicating ${ }^{111}$ In associated with CNT. As expected, the control mixture containing the low-molecular-weight radiolabeled DOTA and $\mathbf{2}$ cleared completely from the mice within a few hours (data not shown).

\section{DISCUSSION}

CNT are being actively investigated as platforms for the delivery of biologic, radiologic, and chemical cargo to target tissues. The potential for the biomedical application of CNT-based materials has been proposed in the literature $(1-6,14)$ based largely on the ability to synthesize constructs and their evaluation in vitro. However, a key question with regard to the suitability of these nanomate-

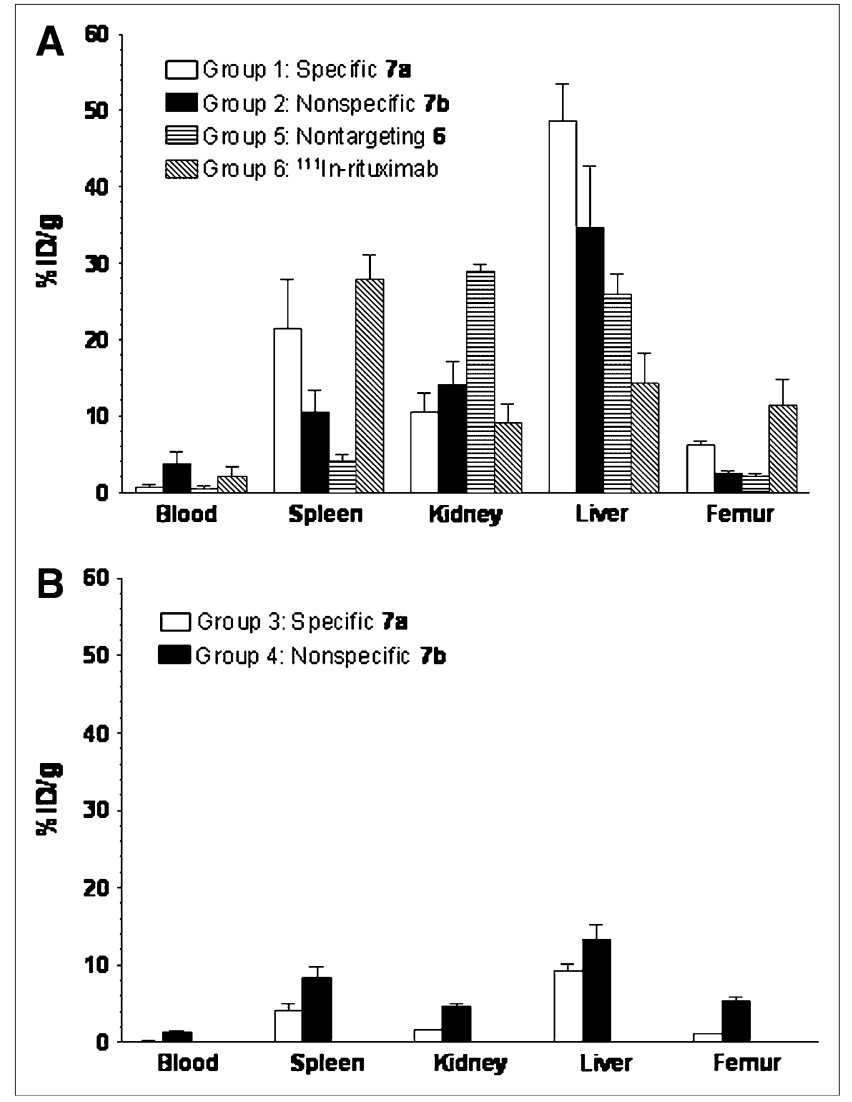

FIGURE 5. Biodistribution data (\%ID/g values [mean $\pm \mathrm{SD}$ ]) of CNT constructs and controls in scid mice with $\mathrm{GFP}^{+} / \mathrm{FFLuc}^{+}$ Daudi tumor (A) and without tumor (B).

rials for biomedical application is how they interface with biologic systems. Issues regarding toxicity have been raised $(15,16)$ and addressed with data showing that solubilization and sidewall functionalization of the CNT mitigates reported toxicity $(17,18)$. The biodistribution of a ${ }^{125}$ I-labeled hydroxylated CNT into the stomach, kidney, and bone in mice (19) can be contrasted with another report (20) describing the rapid blood and whole-body clearance of an ${ }^{111}$ In-DTPA-derivatized CNT (DTPA is diethylenetriaminepentaacetic acid) from mice. Our data for 6, reported herein, support the former article, as we also see radioactivity accumulated in the kidney, spleen, liver, and, to a lesser extent, bone. DOTA-NCS was selected as the chelate because of the strong binding affinity of this octadentate macrocycle, as compared with DTPA anhydride, for many different metal-ions and also for the excellent in vivo stability of the thiourea linkage $(25,35,36)$ to the CNT.

The appending of targeting antibodies to CNT to yield prototype constructs and the evaluation of their ability to target and deliver a radionuclide payload to tumor in vitro and in vivo represents a major advance in this field. In addition, this study quantifies the tumor uptake in vivo and reports clearance from the blood and the distribution to other key organs. Studies with targeting dendrimer constructs have been reported (37), but these only qualitatively 


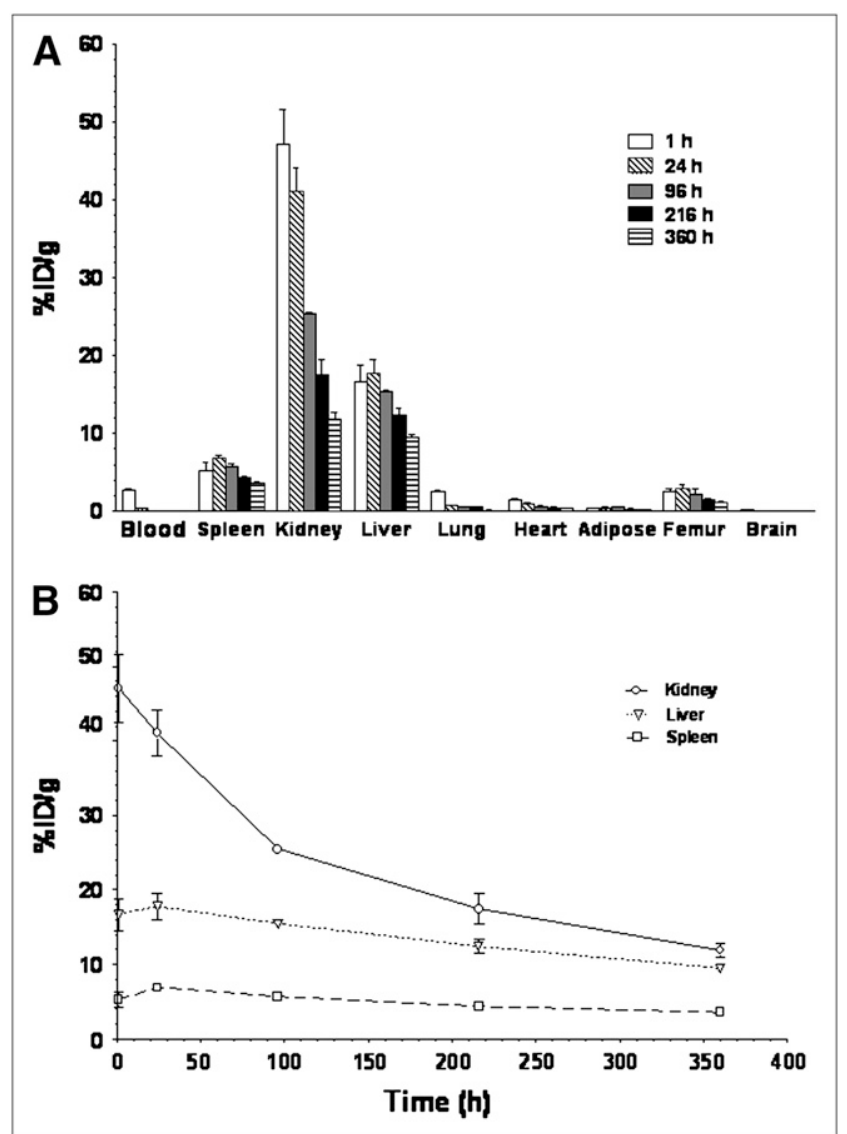

FIGURE 6. (A) Biodistribution data (\%ID/g values [mean \pm SD]) after administration of 6 in nontumor-bearing mice. (B) Clearance of radioactivity from kidney, liver, and spleen as a function of time after administration of 6 .

assess tumor uptake and do not report the \%ID/g of uptake in the tumor or other tissues.

A potential advantage to the use of these CNT materials is based on the enormous aspect ratio that they exhibit. This permits the appending of multiple copies of various moieties along the CNT axis. CNT, in effect, would accommodate amplification of chelate moieties without sacrificing immunoreactivity, relative to antibody-based constructs $(12,13)$. For example, a 200-nm-long CNT in this study was determined to have 114 available DOTA chelates and 6 intact antibodies per construct molecule. CNT constructs could provide a significant amplification in diagnostic or therapeutic function by increasing the number of isotopes delivered per cell. Such amplification would be an important advance because current methods label only a small fraction of the antibodies-for example, only one ${ }^{225} \mathrm{Ac}$ isotope is present per 775 "labeled" antibodies (29). It was observed that 3 could be radiolabeled to very high specific activities with relatively small amounts of CNT (data not included). The size of the construct 7a (approximately $1,300 \mathrm{kDa}$ ) may present an issue for targeting solid tumors, but 7a seemed to have been able to target disseminated lymphoma in a mouse model, and similarly sized constructs could also find application in vascular targeting strategies. Typical specific targeting monoclonal antibodies in animal models of disease exhibit uptake in the range of $10 \% \mathrm{ID} / \mathrm{g}$, but uptake is often less than this value $(38,39)$.

Improved targeting might also be expected from constructs with amplified targeting moieties (40), although this was not demonstrated by these prototypes. 7a was observed to specifically target human lymphoma in vivo as compared with controls $\mathbf{7 b}, \mathbf{6}$, and [ [111 In]Rituximab. Another similar anti-CD20 antibody, when radiolabeled with ${ }^{90} \mathrm{Y}$, yields $\left[{ }^{90} \mathrm{Y}\right]$-ibritumomab, which represents the state of the art in targeted radioimmunotherapy and is the most effective anticancer antibody currently available. In these studies [ ${ }^{111}$ In]Rituximab targeted similarly, but still better than our construct 7a. Given that 7a was a prototype construct design, with a potential mixture of correctly and incorrectly positioned appended antibodies, binding in vitro $(29 \% \pm$ $0.5 \%)$ was comparable to Rituximab $(42 \% \pm 17 \%)$ and a factor of 2 less effective in vivo. Construct 7a did serve as proof-of-concept that this approach was feasible.

These constructs evolved from the performance of simple to increasingly more complex functions, and the CNT platform with its high aspect ratio readily accommodated the different appended moieties. Other nanomaterials, such as dendrimers, have been multifunctionalized to provide quite complex constructs $(9,10)$ and have been evaluated in vivo $(11,37)$. The geometry of interaction of these nanomaterials with cells may play a crucial role in their utility with advantages imparted to either "linear" or "point source" structures. For example, cells with low specific antigen density might be better targeted with linear constructs having antibodies appended along the construct's axis rather than a point source construct with the antibodies essentially at one hub. The linear structure could potentially span up to a micron-sized radius on the topographic surface of the cell and have distal antibodies interact and bind to other antigenic epitopes, thus improving the reactivity with the cell. Also, proteins such as antibodies can target cells and they can be modified further to deliver toxic payloads or report location, but ultimately they may lose their inherent ability to target and bind to a specific epitope when they are too greatly functionalized $(12,13)$. The further exploration and development of both materials is warranted given their novel properties and results thus far.

The constructs described in this study were demonstrated to perform their functions when tasked to target a cancer cell epitope and report location. Assuming that one could also chelate a therapeutic radioisotope such as ${ }^{225} \mathrm{Ac}$ or ${ }^{90} \mathrm{Y}$ to $\mathbf{5 a}$, then the specific delivery of a therapeutic payload to a cancer cell could be effected.

Significant technical hurdles with this platform remain, however. Accumulation of $\mathbf{7 a}$ in the normal liver and kidney (about $10-15 \% \mathrm{ID} / \mathrm{g}$ ) may not be clinically acceptable if appended cytotoxic agents accumulate there as well. The liver uptake of both the specific 7a and the nonspecific $7 \mathbf{b}$ construct molecules was $2-3$ times higher than 
$\left[{ }^{111} \mathrm{In}\right]$ Rituximab alone (15\% $\% \mathrm{ID} / \mathrm{g}$ in the liver). Further understanding of the reasons for accumulation and clearance of these structures in normal tissue is crucial for further development. The covalent attachment of antibody molecules to the CNT dramatically altered the kidney biodistribution and pharmacokinetics, as illustrated by the comparison of $\mathbf{6}$ and 7a in tumor-bearing versus nontumorbearing mice (Figs. 5 and 6). This represents another area to investigate and understand to predict modifications that could effect alteration of the pharmacokinetic profile.

Clearly, the ability to specifically target tumor was antibody-mediated and was not determined by the CNT portion of the construct, as more of the specific construct 7a accumulated in the femur of tumor-bearing mice than did nontargeting, nonantibody-appended construct $\mathbf{6}$.

\section{CONCLUSION}

A key achievement in these studies was the selective targeting of tumor with a soluble, nanoscale CNT construct mediated by appended specific antibodies. The soluble, reactive CNT platform 2 was used as the starting point to build multifunctional constructs with appended antibody, metal-ion chelate, and fluorescent chromophore moieties to effect specific targeting, to carry and deliver a radiometal-ion, and to report location, respectively. The ability to specifically target tumor cells in vitro and tumor in vivo with prototype radiolabeled or fluorescent-labeled, antibodyappended CNT constructs was encouraging and suggested further investigation of CNT as a novel delivery platform.

\section{ACKNOWLEDGMENTS}

This research was supported by NIH grants CA55349 and CA33049, the Tudor and Glades Foundation, the Commonwealth Cancer Foundation for Research, the Experimental Therapeutics Center, and the Laurie Strauss Foundation. We thank Amy Carol McDevitt for assistance with the artwork and figures.

\section{REFERENCES}

1. Hartgerink JD, Beniash E, Stupp SI. Peptide-amphiphile nanofibers: a versatile scaffold for the preparation of self-assembling materials. Proc Natl Acad Sci U SA. 2002;99:5133-5138.

2. Pastorin G, Wu W, Wieckowski S, et al. Double functionalization of carbon nanotubes for multimodal drug delivery. Chem Commun (Camb). 2006;11:11821184.

3. in het Panhuis M. Vaccine delivery by carbon nanotubes. Chem Biol. 2003;10: 897-898.

4. Shi Kam NW, Jessop TC, Wender PA, Dai HJ. Nanotube molecular transporters: internalization of carbon nanotube-protein conjugates into mammalian cells. J Am Chem Soc. 2004;126:6850-6851.

5. Pantarotto D, Briand JP, Prato M, Bianco A. Translocation of bioactive peptides across cell membranes by carbon nanotubes. Chem Commun (Camb). 2004; 7:16-17.

6. Bianco A, Hoebeke J, Godefroy S, et al. Cationic carbon nanotubes bind to $\mathrm{CpG}$ oligodeoxynucleotides and enhance their immunostimulatory properties. J Am Chem Soc. 2005;127:58-59.

7. Cherukuri P, Bachilo SM, Litovsky SH, Weisman RB. Near-infrared fluorescence microscopy of single-walled carbon nanotubes in phagocytic cells. J Am Chem Soc. 2004;126:15638-15639.
8. Dresselhaus MS, Avouris P. Introduction to carbon materials research. Top Appl Phys. 2001;80:1-9.

9. Majoros IJ, Myc A, Thomas T, Mehta CB, Baker JR Jr. PAMAM dendrimerbased multifunctional conjugate for cancer therapy: synthesis, characterization, and functionality. Biomacromolecules. 2006;7:572-579.

10. Patri AK, Myc A, Beals J, et al. Synthesis and in vitro testing of J591 antibodydendrimer conjugates for targeted prostate cancer therapy. Bioconjug Chem. 2004;15:1174-1181.

11. Talanov VS, Regino CA, Kobayashi H, Bernardo M, Choyke PL, Brechbiel MW. Dendrimer-based nanoprobe for dual modality magnetic resonance and fluorescence imaging. Nano Lett. 2006;6:1459-1463.

12. Nikula TK, Bocchia M, Curcio MJ, et al. Impact of the high tyrosine fraction in complementary determining regions: measured and predicted effects of radioiodination on IgG radioimmunotherapy. Mol Immunol. 1995;32:865-872.

13. Hamblett KJ, Senter PD, Chace DF. Effects of drug loading on the antitumor activity of a monoclonal antibody drug composite. Clin Cancer Res. 2004;10: 7063-7070.

14. Kam NW, O'Connell M, Wisdom JA, Dai HJ. Carbon nanotubes as multifunctional biological transporters and near-infrared agents for selective cancer cell destruction. Proc Natl Acad Sci U S A. 2005;102:11600-11605.

15. Shvedova AA, Castranova V, Kisin ER, et al. Exposure to carbon nanotube material: assessment of nanotube cytotoxicity using human keratinocyte cells. J Toxicol Environ Health A. 2003;66:1909-1926.

16. Nel A, Xia T, Madler L, Li N. Toxic potential of materials at the nanolevel. Science. 2006;311:622-627.

17. Sayes CM, Liang F, Hudson J.L, et al. Functionalization density dependence of single-walled carbon nanotubes cytotoxicity in vitro. Toxicol Lett. 2006;161: $135-142$.

18. Dumortier H, Lacotte S, Pastorin G, et al. Functionalized carbon nanotubes are non-cytotoxic and preserve the functionality of primary immune cells. Nano Lett. 2006;6:1522-1528.

19. Wang H, Wang J, Deng X, et al. Biodistribution of carbon single-wall nanotubes in mice. J Nanosci Nanotechnol. 2004;4:1019-1024.

20. Singh R, Pantarotto D, Lacerda L, et al. Tissue biodistribution and blood clearance rates of intravenously administered carbon nanotube radiotracers. Proc Natl Acad Sci U S A. 2006;109:3357-3362.

21. Mammen M, Choi SK, Whitesides GM. Polyvalent interactions in biological systems: implications for design and use of multivalent ligands and inhibitors. Angew Chem Int Ed Engl. 1998;37:2755-2794.

22. Chattopadhyay D, Galeska I, Papadimitrakopoulos F. Complete elimination of metal catalysts from single wall carbon nanotubes. Carbon. 2002;40: 985-988.

23. Georgakilas V, Tagmatarchis N, Pantarotto D, Bianco A, Briand JP, Prato M. Amino acid functionalisation of water soluble carbon nanotubes. Chem Commun. 2002;12:3050-3051.

24. Sarin VK, Kent SBH, Tam JP, Merrifield RB. Quantitative monitoring of solid-phase peptide synthesis by ninhydrin reaction. Anal Biochem. 1981;117: $147-157$.

25. McDevitt MR, Ma D, Lai LT, et al. Tumor therapy with targeted atomic nanogenerators. Science. 2001;294:1537-1540.

26. Nikula TK, Curcio MJ, Brechbiel MW, Gansow OA, Finn RD, Scheinberg DA. A rapid, single vessel method for preparation of clinical grade ligand conjugated monoclonal antibodies. Nucl Med Biol. 1995;22:387-390.

27. Dadachova E, Chappell LL, Brechbiel MW. Spectrophotometric method for determination of bifunctional macrocyclic ligands in macrocyclic ligand-protein conjugates. Nucl Med Biol. 1999;26:977-982.

28. Ellman GL. Tissue sulfhydryl groups. Arch Biochem Biophys. 1959;82:70-77.

29. McDevitt MR, Ma D, Simon J, Frank RK, Kiefer GE, Scheinberg DA. Design and synthesis of ${ }^{225} \mathrm{Ac}$ radioimmunopharmaceuticals. Appl Radiat Isot. 2002;57:841-847.

30. Latouche JB, Sadelain M. Induction of human cytotoxic T lymphocytes by artificial antigen-presenting cells. Nat Biotechnol. 2000;18:405-409.

31. Riviere I, Brose K, Mulligan RC. Effects of retroviral vector design on expression of human adenosine deaminase in murine bone marrow transplant recipients engrafted with genetically modified cells. Proc Natl Acad Sci U S A. 1995;92:6733-6737.

32. Terwey TH, Kim TD, Kochman AA, et al. CCR2 is required for CD8-induced graft-versus-host disease. Blood. 2005;106:3322-3330.

33. Ghetie MA, Richarson J, Tucker T, Jones D, Uhr JW, Vitetta ES. Disseminated or localized growth of a human B-cell tumor (Daudi) in scid mice. Int J Cancer. 1990;45:481-485.

34. Ma D, McDevitt MR, Barendswaard E, et al. Radioimmunotherapy for model B cell malignancies using ${ }^{90} \mathrm{Y}$-labeled anti-CD19 and anti-CD20 monoclonal antibodies. Leukemia. 2002;16:60-66. 
35. Esteban JM, Schlom J, Gansow OA, et al. New method for the chelation of indium-111 to monoclonal antibodies: biodistribution and imaging of athymic mice bearing human colon carcinoma xenografts. J Nucl Med. 1987;28: 861-870.

36. Ruegg CL, Anderson-Berg WT, Brechbiel MW, Mirzadeh S, Gansow OA, Strand M. Improved in vivo stability and tumor targeting of bismuth-labeled antibody. Cancer Res. 1990;50:4221-4226.

37. Shukla R, Thomas TP, Peters JL, et al. HER 2 specific tumor targeting with dendrimer conjugated anti-HER2 mAb. Bioconjug Chem. 2006;17:1109-1115.
38. Sharkey RM, Primus FJ, Goldenberg DM. Second antibody clearance of radiolabeled antibody in cancer radioimmunodetection. Proc Natl Acad Sci U S A. 1984;81:2843-2846.

39. Mueller BM, Reisfeld RA, Gillies SD. Serum half-life and tumor localization of a chimeric antibody deleted of the $\mathrm{CH} 2$ domain and directed against the disialoganglioside GD2. Proc Natl Acad Sci U S A. 1990;87:5702-5705.

40. Kok RJ, Schraa AJ, Bos EJ, et al. Preparation and functional evaluation of RGDmodified proteins as $\alpha v \beta 3$ integrin directed therapeutics. Bioconjug Chem. 2002;13:128-135. 